\title{
Organogel Coupled with Microstructured Electrospun Polymeric Nonwovens for the Effective Cleaning of Sensitive Surfaces
}

\author{
Yiming Jia, Giorgia Sciutto, Rocco Mazzeo, Chiara Samorì, Maria Letizia Focarete, Silvia Prati,* \\ and Chiara Gualandi*
}

Cite This: ACS Appl. Mater. Interfaces 2020, 12, 39620-39629

Read Online

ABSTRACT: Hydrogels and organogels are widely used as cleaning materials, especially when a controlled solvent release is necessary to prevent substrate damage. This situation is often encountered in the personal care and electronic components fields and represents a challenge in restoration, where the removal of a thin layer of aged varnish from a painting may compromise the integrity of the painting itself. There is an urgent need for new and effective cleaning materials capable of controlling and limiting the use of solvents, achieving at the same time high cleaning efficacy. In this paper, new sandwich-like composites that fully address these requirements are developed by using an organogel (poly(3hydroxybutyrate $)+\gamma$-valerolactone) in the core and two external layers of electrospun nonwovens made of continuous submicro-

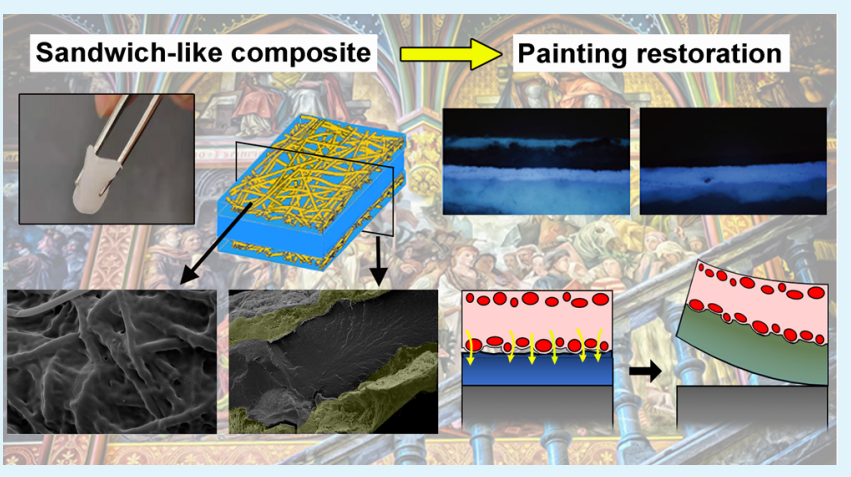
metric fibers produced by electrospinning (either poly(vinyl alcohol) or polyamide 6,6). The new composite materials exhibit an extremely efficient cleaning action that results in the complete elimination of the varnish layer with a minimal amount of solvent adsorbed by the painting layer after the treatment. This demonstrates that the combined materials exert a superficial action that is of utmost importance to safeguard the painting. Moreover, we found that the electrospun nonwoven layers act as mechanically reinforcement components, greatly improving the bending resistance of organogels and their handling. The characterization of these innovative cleaning materials allowed us to propose a mechanism to explain their action: electrospun fibers play the leading role by slowing down the diffusion of the solvent and by conferring to the entire composite a microstructured rough superficial morphology, enabling to achieve outstanding cleaning performance.

KEYWORDS: organogel, polyhydroxyalkanoates, electrospinning, composite material, Dammar varnish

\section{INTRODUCTION}

Soft hydrogels and organogels combined with suitable solvents are commonly employed for the cleaning of dirty surfaces, especially when the substrate is susceptible to swelling and its functionality is compromised by the solvent itself. This is a frequent issue encountered in art restoration as well as in personal care and electronics. In these frameworks, the benefits of gels rely on their capability to entrap the solvent to minimize substrate damage and to adapt their shape to maximize the contact with the surface, necessary to achieve good cleaning efficiency. A typical application of hydrogels and organogels is the selective removal of varnish layers from paintings. ${ }^{1-4}$ Traditionally, natural resins, such as dammar and shellac, have been widely used for the preparation of varnishes. ${ }^{5}$ With the passing of time, natural resins change their chemical, optical, and mechanical properties because of the oxidative actions of light, air, and the interaction with pollutants. ${ }^{6,7}$ The most common procedure for the removal of the discolored and degraded varnishes consists in applying solvents with cotton swabs. However, this approach is extremely risky for the painting because the solvent action is highly uncontrollable and leads to saponification, swelling, and leaching of the painting layer components, with decrease of the surface mechanical strength. ${ }^{8-10} \mathrm{~A}$ valid alternative is the use of gels able to exert a controlled solvent action. Consequently, chemical and physical gels have become popular for the removal of aged varnishes or coatings from artwork surfaces through a "press and peel" approach. ${ }^{1-3,11-13}$ Gels used in restoration have different physical aspects: viscous dispersions, sticky masses, flexible, and peelable films. ${ }^{3,4}$ Gel-solvent interaction and chemical/physical cross-links affect both solvent retention and mechanical properties, thus determining the final cleaning efficacy, the presence of gel residues, the

Received: May 26, 2020

Accepted: August 7, 2020

Published: August 21, 2020 


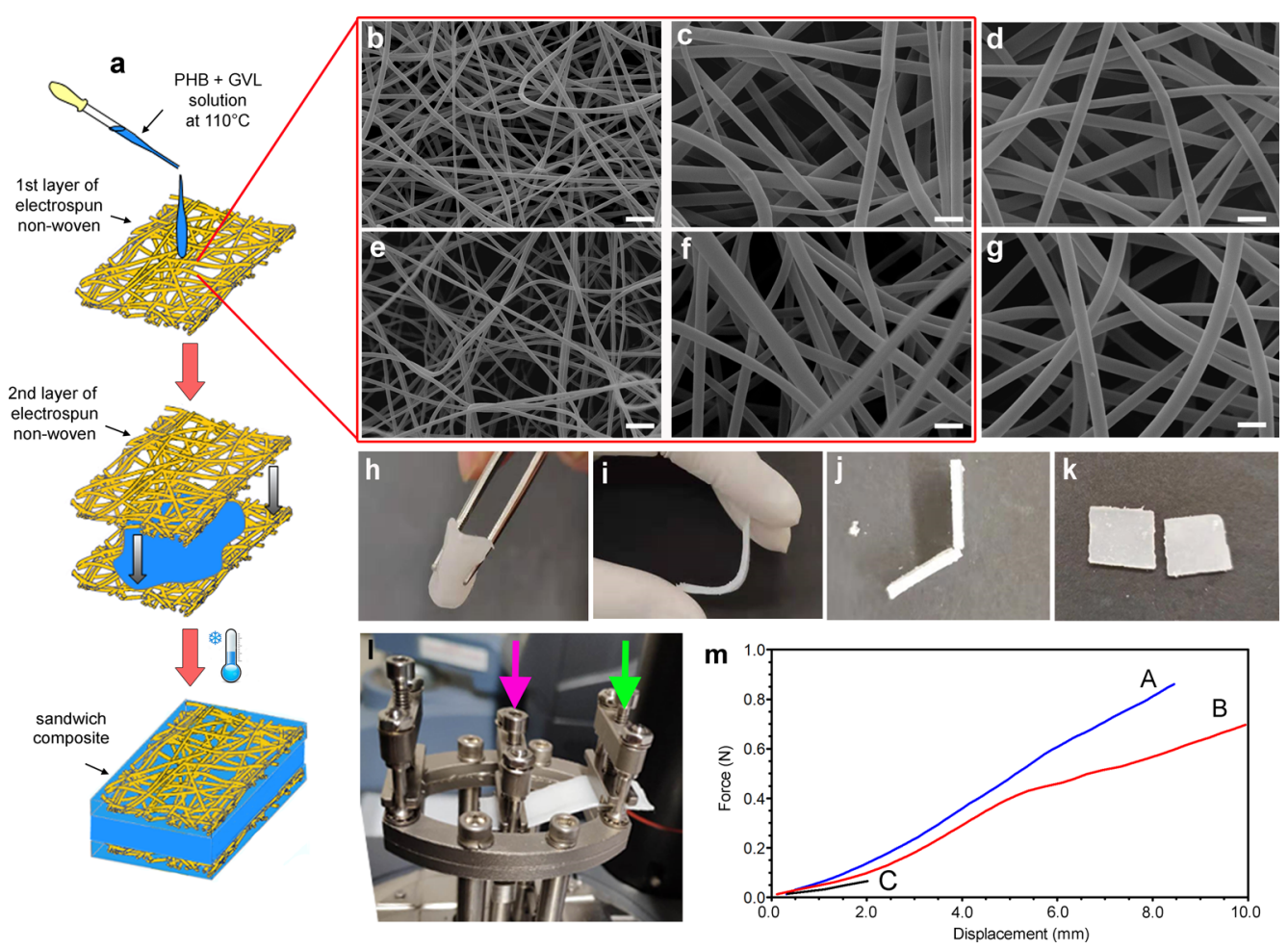

Figure 1. Sketch describing the preparation of PA6,6/PHB-GVL and PVA/PHB-GVL sandwich-like composites (a). SEM images of PA6,6 (b,c) and PVA (e,f) fibers at different magnifications; PA6,6 (d) and PVA (g) fibers after immersion in GVL for 1 min at $110{ }^{\circ} \mathrm{C}$ and dried at RT. Representative pictures of sandwich-like composite $(\mathrm{h}, \mathrm{i})$ and PHB-GVL gel $(\mathrm{j}, \mathrm{k})$ showing the different mechanical resistance of the two types of materials under bending. (1) Single cantilever configuration for sample mounting, where the green arrow indicates the fixed clamp and the pink arrow indicates the movable clamp (a representative composite sample is mounted in the picture). (m) Force-displacement curves of PA6,6/PHBGVL composite (blue, A), PVA/PHB-GVL composite (red, B), and PHB-GVL gel (black, C): composites resist up to $10 \mathrm{~mm}$ bending, whereas the gel breaks at $2 \mathrm{~mm}$. Scale bar: $6 \mu \mathrm{m}(\mathrm{b}, \mathrm{e}) ; 2 \mu \mathrm{m}(\mathrm{c}, \mathrm{d}, \mathrm{f}, \mathrm{g})$.

safety for the underneath substrate, and the ease of use. ${ }^{14,15}$ Generally, low elastic moduli are desired to maximize the contact with the surface to achieve better cleaning at the expense, however, of retention capability and gel cohesion, with a consequent uncontrolled release of solvent, undesired painting damages, and residues on the object. Therefore, when designing gels for such a kind of applications, the challenge is to find a good compromise between gel softness and solvent retention.

We have recently proposed poly-3-hydroxybutyrate (PHB)based gels with green solvents as new cleaning systems for paintings and indoor bronzes ${ }^{16-18}$ addressing the demand of green bio-based cleaning approaches, ${ }^{19-25}$ to the benefit not only of the artworks, but also of restorers and the environment. A step forward for optimizing the use of these gels is the improvement of their cleaning efficiency, solvent retention, handling, and mechanical properties in order to avoid their fragmentations when they are applied or removed. To this aim, the combination of gels with mechanical resistant materials in a composite structure is expected to provide relevant benefits.

Nonwoven fabrics of continuous micrometric fibers made by electrospinning technology have unique properties, such as interconnected and open porosity, high surface area, liquid permeability, excellent flexibility, and mechanical resistance, ${ }^{26,27}$ which make them ideal materials to act as reinforcing components for organogels. Electrospinning is a polymer processing technique that uses electrostatic forces to stretch a viscoelastic jet derived from a polymer solution. Electrospun fibers are currently used for a wide range of applications, including filtration, sensors, catalytic systems, energy storage, structural composites, and biomedical applications. ${ }^{28-31}$ Electrospinning is a consolidate technology on a lab-scale dimension and the scaling up toward levels feasible for mass production has been realized in the past decade by several companies. $^{32}$

Electrospun materials have been already used in combination with soft gels for applications in the biomedical field. Here, their unique structures and properties ${ }^{33}$ have been exploited for enhancing gel mechanical properties ${ }^{34-36}$ and various combination strategies have been adopted to obtain different kind of fibers-hydrogel composites. ${ }^{37-41}$ Moreover, the use of fibers with submicrometric diameters confers to the gel a surface microstructuration that is considered highly advantageous for tissue engineering applications. ${ }^{42}$

With these premises, in this work, we propose for the first time the use of new sandwich-like composites based on the combination of electrospun polymers, that is, poly(vinyl alcohol) (PVA) and polyamide 6,6 (PA6,6), with the PHBbased organogel. In these composites, electrospun mats act as external mechanically resistant layers and provide microstructuration on the surface of the composite. The gel constitutes the core and contains the active solvent, which in turn exerts its function by diffusing through the pores of the electrospun layer toward the paint. PA6,6/PHB-GVL and PVA/PHB-GVL composites have been produced and their mechanical properties, morphology, and composition have been characterized. Their capability to remove a varnish layer made with a terpenic material applied on a paint mock-up and 
prepared by following ancient recipes ${ }^{43}$ was also tested. Finally, a possible mechanism was suggested to explain why the composite materials produce a limited and superficial release of solvent and at the same time are able to exhibit exceptional cleaning performances.

\section{EXPERIMENTAL PART}

Materials. $\gamma$-Valerolactone (GVL), PHB, PVA $\left(M_{\mathrm{w}}=85,000-\right.$ $124,000 \mathrm{~g} / \mathrm{mol}, 87-89 \%$ hydrolyzed), 1,1,1,3,3,3-hexafluoro-2-propanol (HFIP), absolute ethanol (EtOH), and $\gamma$-butyrolactone (BL) were purchased from Sigma-Aldrich. PA6,6 (Zytel E53 NC010) was kindly provided by DuPont. All of the chemical reagents were commercially available and directly used without treatment.

Fabrication of PVA and PA6,6 Electrospun Nonwoven Fabrics. The electrospinning apparatus, made in-house, was composed by a high voltage power supply (Spellman SL 50 P 10/ $\mathrm{CE} / 230$ ), a syringe containing the polymeric solution connected to a stainless steel blunt-ended needle (inner diameter: $0.51 \mathrm{~mm}$ ), and a grounded aluminum rotating mandrel as a collector (length $=12 \mathrm{~cm}$, diameter $=5 \mathrm{~cm}$ ). The polymeric solution was dispensed through a polytetrafluoroethylene (PTFE) tube to the needle that was vertically placed on the collector. PVA was dissolved in $\mathrm{EtOH} / \mathrm{H}_{2} \mathrm{O}(1 / 1 \mathrm{v} / \mathrm{v})$ at a concentration of $10 \% \mathrm{w} / \mathrm{v}$ and stirred until all the polymer dissolved in the solvent at room temperature (RT). PVA nonwoven was fabricated using the following conditions: applied voltage $16 \mathrm{kV}$, needle-to-collector distance $18 \mathrm{~cm}$, solution flow rate $1.5 \mathrm{~mL} / \mathrm{h}$, at RT, and relative humidity $40-50 \%$. PA6,6 was dissolved in HFIP at a concentration of $20 \% \mathrm{w} / \mathrm{v}$ and stirred until all of the polymer dissolved at RT. PA6,6 nonwoven was fabricated using the following conditions: applied voltage $20 \mathrm{kV}$, needle-to-collector distance $15 \mathrm{~cm}$, solution flow rate $0.5 \mathrm{~mL} / \mathrm{h}$, at RT, and relative humidity $40-50 \%$. Electrospun samples have a final dimension of about $15 \times 8 \mathrm{~cm}^{2}$ and a thickness in the range $70-110 \mu \mathrm{m}$.

Preparation of the PHB-GVL Organogel. PHB-GVL gels were produced according to a previously reported procedure. ${ }^{16}$ Briefly, $300 \mathrm{mg}$ of PHB were solubilized in $3 \mathrm{~mL}$ of GVL, in a closed vial, by stirring at $110^{\circ} \mathrm{C}$ for $5 \mathrm{~min}$ in an oil bath, until all the PHB powder dissolved in the solution and became transparent. The solution was then poured in a Petri dish and cooled down to RT to obtain an opalescent and stiff gel about $3 \mathrm{~mm}$ thick.

Preparation of the Sandwich-Like Composites. Figure 1a reports the procedure for the preparation of PVA/PHB-GVL and PA6,6/PHB-GVL sandwich-like composites. PHB-GVL $(200 \mu \mathrm{L})$ solution prepared at $110^{\circ} \mathrm{C}$ was dropped onto a layer of electrospun nonwoven (typically $1 \times 1 \mathrm{~cm}^{2}$ ). During this step, the PHB-GVL solution well-impregnated the pores of the electrospun tissue by homogeneously spreading over the entire surface of the nonwoven. A second layer of electrospun nonwoven was quickly laid on the top of the PHB solution by manually applying a slight pressure. The duration of the dropping and of the application of the second layer was controlled to be not longer than $30 \mathrm{~s}$. The solution instantaneously wetted and impregnated the second fabric. The system was finally let to cool down to RT, obtaining a final sandwichlike composite with thickness in the range 1.7-1.9 mm (see Table S1 for details on the geometry of the composites). No shrinkage is observed immediately after the preparation (Figure S1). The composites were employed for mock-ups cleaning within $30 \mathrm{~min}$ from the preparation. In this time interval, no relevant modification of the sample shape was detected (Figure S1).

Characterisation of the PHB-GVL Gel and Sandwich-Like Composites. Sample morphology was observed with a scanning electron microscope (SEM, Leica Cambridge Stereoscan 360) at an accelerating voltage of $20 \mathrm{kV}$. Prior to SEM analysis, the samples were dried in an oven at $T=40^{\circ} \mathrm{C}$ for 15 days to remove the GVL solvent, and sputtered with gold. The distribution of fiber diameters was determined through the measurement of about 100 fibers and the results were given as the average diameter \pm standard deviation. The student unpaired $t$-test was used to test the statistical significance of the difference between the mean values $(p<0.05)$. Thermogravi- metric analyses (TGA) were carried out using a TGA Q500 thermogravimetric analyzer (TA Instruments). The thermograms were recorded from RT to $700{ }^{\circ} \mathrm{C}$ at a heating rate of $10{ }^{\circ} \mathrm{C} / \mathrm{min}$ under the $\mathrm{N}_{2}$ atmosphere. TGA analysis was performed twice on the composites to verify the reproducibility of the result. The mechanical characterization of the materials was carried out using a Dynamic Mechanical Analyzer DMA Q800 (TA Instruments) in single cantilever configuration at RT. The analyses were performed on rectangular strips (width $15 \mathrm{~mm}$; gauge length about $18 \mathrm{~mm}$ ) whose thickness was measured by a digital caliper. Two replicas for each sample were carried out by applying a ramp force of $1 \mathrm{~N} / \mathrm{min}$ until sample break. Differential scanning calorimetry (DSC) was carried out under the $\mathrm{N}_{2}$ atmosphere by means of a differential scanning calorimeter (DSC Q100; TA Instruments) equipped with a refrigerated cooling system. Electrospun samples were kept at 50 ${ }^{\circ} \mathrm{C}$ for $1 \mathrm{~h}$ under $\mathrm{N}_{2}$ flow $(50 \mathrm{~mL} / \mathrm{min})$ to eliminate most of the absorbed water and were subsequently subjected to two heating scans at $20^{\circ} \mathrm{C} / \mathrm{min}$ and one fast cooling applied between the heating scans.

Rheological experiments were carried out on an Anton Paar rheometer MCR 102 using a cone-plate configuration $(50 \mathrm{~mm}$ diameter). The temperature was controlled by an integrated Peltier system and a Julabo AWC100 cooling system. To keep the sample wet during the measure, a solvent trap was used (H-PTD200). The temperature sweep analyses during cooling rate scans $(1,5$ and 10 ${ }^{\circ} \mathrm{C} / \mathrm{min}$ ) were performed with a fixed gap value of $0.102 \mathrm{~mm}$ at a constant strain of $0.5 \%$ and frequency of $10 \mathrm{rad} / \mathrm{s}$. The PHB-GVL solutions were prepared at $120^{\circ} \mathrm{C}$ and transferred on the hot plate of the rheometer kept at $140{ }^{\circ} \mathrm{C}$. The solution was maintained for $3 \mathrm{~min}$ in the hot cone-plate before starting the test. The viscosity of the solution was also monitored during a cooling scan at $10{ }^{\circ} \mathrm{C} / \mathrm{min}$ by applying a strain rate of $10 \mathrm{l} / \mathrm{s}$.

Cleaning Procedures. To evaluate the cleaning efficiency, the sandwich-like composites were tested on mock-ups and compared with the PHB-GVL gel. The mockups were prepared according to traditional painting techniques, and naturally aged over 2.5 years. The preparation layer was made of gypsum and rabbit glue, dissolving 1.0 $\mathrm{g}$ of animal glue in $5.0 \mathrm{~mL}$ of hot distilled water and mixing it with 6.0 $\mathrm{g}$ of grinded gypsum. The pigment layer was obtained by dissolving $2.0 \mathrm{~g}$ of red burnt ochre in $2.0 \mathrm{~mL}$ of $10 \% \mathrm{w} / \mathrm{w}$ of rabbit glue solution. The varnish layer was prepared by dissolving $1.0 \mathrm{~g}$ of dammar in 2.5 $\mathrm{mL}$ of turpentine. PVA/PHB-GVL, PA6,6/PHB-GVL, and PHBGVL gel were directly applied on the surface of painting mock-ups for $5 \mathrm{~min}$, then the samples were removed and the surface was further cleaned with dry cotton swabs to eliminate the residues of dammar and the excess solvent.

Evaluation of the Cleaning Performances. Cross sections of mock-ups varnished with dammar before and after the cleaning treatment were observed by optical microscopy in visible and ultraviolet light (Olympus Optical Microscope BX51, Tokyo, Japan). Attenuated total reflectance (ATR) analyses were performed with a Thermo Nicolet (Thermo Fisher Scientific, Waltham, MA, USA), iN10MX imaging microscope, fitted with a mercurycadmium-telluride detector cooled by liquid nitrogen. Measurements were performed using a slide-on ATR objective, equipped with a conical germanium crystal, in the range $4000-675 \mathrm{~cm}^{-1}$, at a spectral resolution of $4 \mathrm{~cm}^{-1}$ with 128 scans and an optical aperture of $150 \times$ $150 \mu \mathrm{m}$. Spectroscopic analysis was performed on 3 different areas treated with the same cleaning procedure and 4 spectra were recorded before and after treatment. Headspace solid phase microextraction (HS-SPME) was employed for the evaluation of the solvent retention into the substrate after the cleaning treatments. ${ }^{16,17}$ Analyses were performed exposing directly a carboxen-polydimethylsiloxane fiber into the headspace of a sealed vial containing the sample. The sample consisted in a fragment of around $1.0 \mathrm{mg}$ collected from the surface of the painting mock-up. Because of the low volatility of GVL, sampling was performed after $2 \mathrm{~h}$ and after $24 \mathrm{~h}$ from the application to better describe the release behavior of the cleaning systems. The sample was placed into a $20 \mathrm{~mL} \mathrm{HS}$ vial, spiked with $1 \mu \mathrm{g}$ of the internal standard (BL) and sealed with a silicone/PTFE septa and aluminum cap (Thermo Fisher Scientific, Waltham, MA, U.S.A.). The SPME fiber 


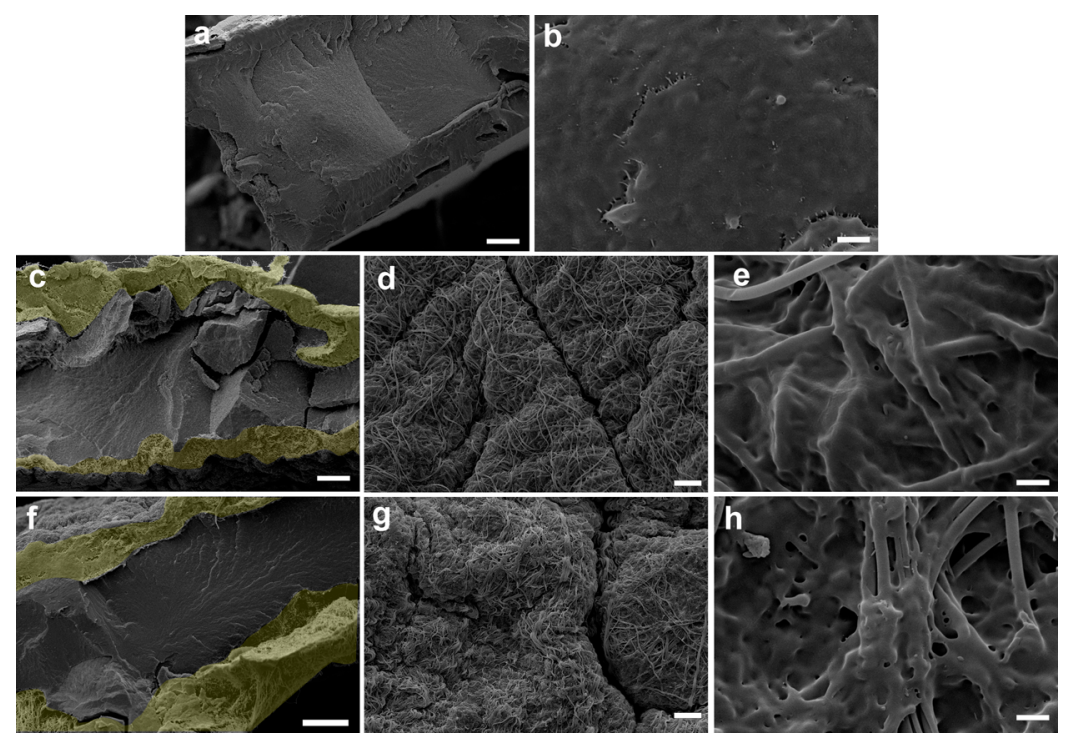

Figure 2. SEM micrographs of PHB-GVL gel (a,b), PA6,6/PHB-GVL composite (c-e), and PVA/PHB-GVL composite (f-h). (a,c,f) are cross-section images where the electrospun layers are highlighted in yellow; (b,d,e,g,h) are images of the external surfaces at different magnifications. Scale bar: $100 \mu \mathrm{m}(\mathrm{a}, \mathrm{c}, \mathrm{f}) ; 20 \mu \mathrm{m}(\mathrm{d}, \mathrm{g}) ; 6 \mu \mathrm{m}(\mathrm{b}) ; 2 \mu \mathrm{m}(\mathrm{e}, \mathrm{h})$.

was inserted into the headspace vial and the sample was thermally heated to $150{ }^{\circ} \mathrm{C}$ for $30 \mathrm{~min}$. After reaching the extraction time, the fiber was inserted into the injector of a 5977 Agilent gas chromatograph connected to a $7820 \mathrm{~A}$ Agilent quadrupole mass spectrometer (Agilent Technologies, Inc., Santa Clara, CA, U.S.A.). Analytes were thermally desorbed at $250{ }^{\circ} \mathrm{C}$ for $15 \mathrm{~min}$ and separated with a DB-FFAP polar column ( $30 \mathrm{~m}$ length, $0.25 \mathrm{~mm}$ i.d., $0.25 \mu \mathrm{m}$ film thickness), using helium as carrier gas. The thermal program was: $100-250{ }^{\circ} \mathrm{C}$ at $10^{\circ} \mathrm{C} \mathrm{min}{ }^{-1}$. The abundances of the individual compounds were quantified from the $m / z 86$ for BL, 100 for GVL mass chromatograms. Calibration curves were performed for BL in the consistent concentration of $1000 \mathrm{ppm}$ in methanol and GVL in the concentration range of 500-8000 $\mathrm{ppm}$ by the regression method. The areas corresponding to this range of concentration of standard solutions are in accordance with those obtained by sample measurements, at least two sample replicas treated with the same procedure were performed to quantify the amount of GVL in the substrate after the cleaning procedure.

\section{RESULTS AND DISCUSSION}

Characterisation of the PHB Gel and Sandwich-Like Composites. Nonwoven fabrics made of randomly oriented fibers of PA6,6 and PVA were fabricated by applying optimized electrospinning conditions to gain continuous, smooth, and bead-free fibers (Figure $1 \mathrm{~b}, \mathrm{c}, \mathrm{e}, \mathrm{f}$ ) with comparable submicrometric diameters $(790 \pm 180 \mu \mathrm{m}$ for PA6,6 and $750 \pm 150 \mu \mathrm{m}$, $p>0.05)$. Both electrospun samples are highly flexible and mechanically resistant to handling. PVA is a water-soluble polymer largely employed for pharmaceutical uses, protective water-soluble films, textile processing, and cosmetics. PA6,6 is used for textiles, in automotive, and for electronic goods. Both polymers are semicrystalline (see DSC in Figure S2), strong but ductile, and both are neither solubilized nor swollen by the GVL solvent.

To optimize the procedure for the preparation of the sandwich-like composites, the rheological properties of the PHB-GVL solution were investigated with the aim to identify the temperature and the dropping conditions for obtaining reproducible results. Figure S3 shows that the temperature of gelation of $\mathrm{PHB}-\mathrm{GVL}$ solution is in the range $75-113{ }^{\circ} \mathrm{C}$, depending on the cooling rate. The data demonstrate that the
PHB-GVL system massively changes its property in a narrow temperature range, thus making the preparation of the composite critical if not performed in the proper conditions. In particular, it was experimentally verified that, to achieve the formation of composites with cohesive layers, the dropping step and the laying of the second electrospun mat must be performed in a time range of about $30 \mathrm{~s}$, before the occurrence of PHB-GVL gelation. It was also verified that, as soon as the PHB-GVL is in the liquid state, the viscosity is not affected by the temperature (Figure S3d), meaning that its percolation in the pores of the electrospun layers is not expected to be influenced by the solution temperature. This information allowed to set the proper dropping conditions in terms of temperature and duration of the procedure, as reported in the "Experimental Part" section.

The stability of the fibers at the PHB-GVL solution was evaluated by means of SEM and DSC. Figure 1d,g shows that the fiber morphology is perfectly preserved in contact with GVL at $110{ }^{\circ} \mathrm{C}$ (i.e., at the temperature of composite preparation). DSC analyses demonstrate that the solid-state structure of fibers, in terms of the amorphous-to-crystalline ratio, is also preserved after GVL treatment (see Figure S2 and the Supporting Information for details).

The sandwich-like composites appear highly flexible and resist to handling and bending (Figure $1 \mathrm{~h}, \mathrm{i}$ ). A remarkable different behavior is displayed by the PHB-GVL gel, that presents a fragile behavior and breaks when slightly bended (Figure 1j,k). The mechanical resistance of the different materials was better evaluated by using a DMA analyzer in single cantilever configuration (Figure 11). Here, the sample was mounted on one side to the fixed clamp (green arrow) and on the other side to the movable clamp (pink arrow). Forcedisplacement curves are shown in Figure $1 \mathrm{~m}$ and clearly show that sandwich-like composites can be bended up to $1 \mathrm{~cm}$ of lateral displacement before breaking and resist to higher forces compared to PHB-GVL gels, which instead breaks after a minimal bending. Therefore, in the sandwich composites, the excellent resistance to handling and deformation of the external layers of electrospun nonwovens is successfully 

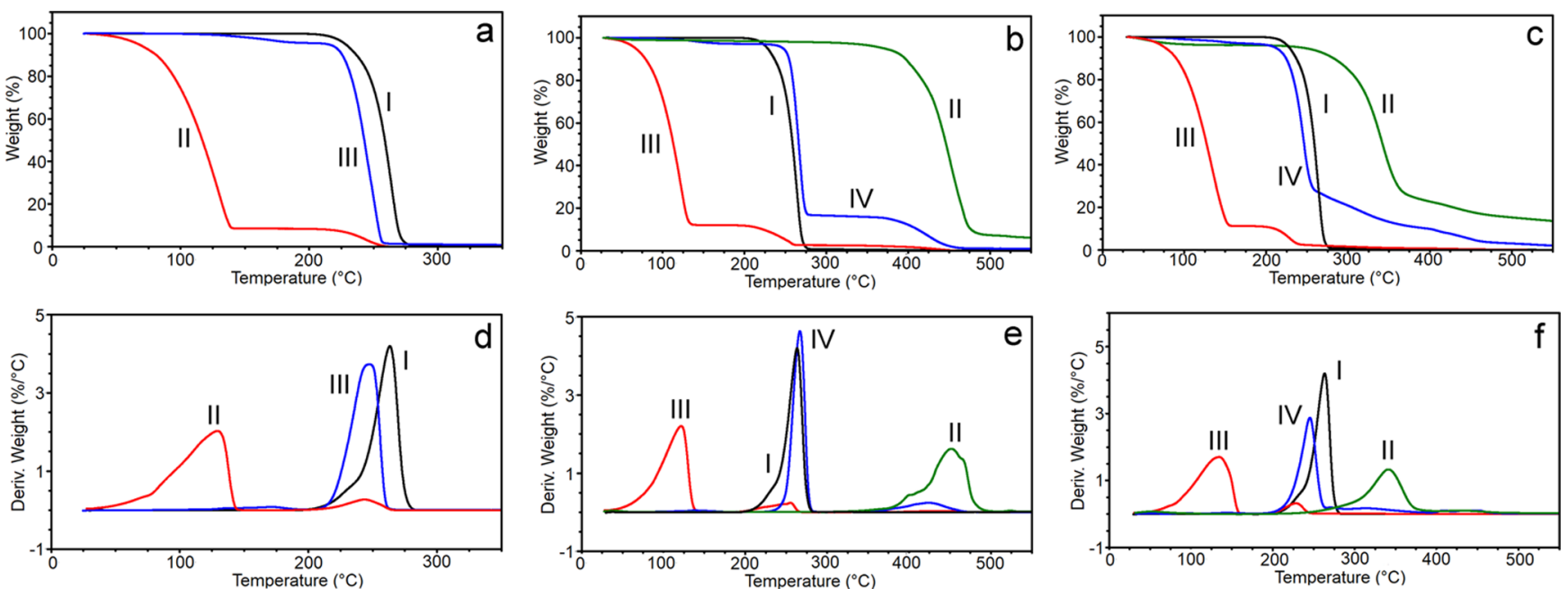

Figure 3. TGA $(\mathrm{a}-\mathrm{c})$ and corresponding derivative TGA $(\mathrm{d}-\mathrm{f})$ curves. In (a,d) (I) PHB, (II) PHB-GVL wet gel, and (III) PHB-GVL dried gel; in (b,e) (I) PHB, (II) PA6,6; (III) PA6,6/PHB-GVL wet composite, and (IV) PA6,6/PHB-GVL dried composite; in (c,f) (I) PHB, (II) PVA; (III) PVA/PHB-GVL wet composite, and (IV) PVA/PHB-GVL dried composite.

Table 1. Thermogravimetric Data for Wet and Dried PHB-GVL Gel and Sandwich Composites, together with Data of Pure Components for Comparison

\begin{tabular}{lcccc}
\multicolumn{1}{c}{ sample } & $\Delta m \%\left(\mathrm{RT}-200{ }^{\circ} \mathrm{C}\right)$ & $\Delta m \%\left(200-300{ }^{\circ} \mathrm{C}\right)$ & $\Delta m \%\left(300-550{ }^{\circ} \mathrm{C}\right)$ & 0 \\
PHB & 0 & 100 & 92 & 0 \\
PA6,6 & 2 & 0 & 71 & $m_{\text {res }}{ }^{a}$ \\
PVA & 4 & 11 & 0 & 14 \\
PHB-GVL wet & 92 & 8 & 0 & 0 \\
PHB-GVL dried & 4 & 94 & 3 & 0 \\
PA6,6/PHB-GVL wet & 88 & 9 & 17 & 0 \\
PA6,6/PHB-GVL dried & 3 & 9 & 2 & 0 \\
PVA/PHB-GVL wet & 89 & 76 & 19 & 2 \\
PVA/PHB-GVL dried & 3 & &
\end{tabular}

${ }^{a}$ Residual mass at $550{ }^{\circ} \mathrm{C}$.

transferred to the gel, accomplishing improved mechanical properties.

The dried PHB-GVL gel and the sandwich-like composites were observed by SEM both at the cross section and at the external surface (Figure 2). The PHB-GVL gel is a single layer structure (Figure $2 \mathrm{a}$ ) with a relatively smooth surface (Figure 2b) devoid of any pores. In the cross-section images of the composites (Figure 2c,f), the two external electrospun layers (highlighted in yellow) are clearly distinguishable from the PHB-GVL core. It is pointed out that the thickness of the different layers in the swollen state is highly affected by the presence of the solvent and cannot be thus determined by SEM. However, SEM cross-sections highlight that the thickness of the external electrospun layers is significantly lower than that of the core, meaning that a few amount of fibers is enough to massively improve the mechanical properties, as discussed above (Figure $1 \mathrm{~h}-\mathrm{m}$ ). Moreover, the shrinkage of the gel core, provoked by the solvent loss during the drying process, induced the curling of the external flexible electrospun layers, being well-adherent to the core part. Evidence of good adhesion is also provided by the images of composite external surfaces (Figure 2d,e,g,h). Here, the fibrous structure is clearly visible while the PHB-GVL component has well-penetrated and impregnated the pores. The presence of the gel component in the pores of the nonwoven, on one side, provides mechanical adhesion between the layers and, on the other side, is crucial for ensuring a good transfer of the cleaning solvent between the inner gel part of the composite and the external layer that will be directly in contact with the painting. Moreover, the microstructuration of the composite surface, thanks to the presence of the fibrous component, clearly determines an increase of surface roughness. From Figure $2 \mathrm{e}, \mathrm{h}$ it is also evident that the gel component, besides filling the pores of the electrospun layer, also entirely surrounds and covers the surface of the fibers (see Figure S4 for additional images). This observation will be crucial for elucidating the cleaning mechanism of the composites.

To gain information on the composition of the PHB-GVL gel and of the composites, TGA analysis was carried out. Figure 3 reports TGA and DTGA curves of both wet and dried gel and composites, together with the pure components (i.e., PHB, PA6,6, and PVA) for comparison. Corresponding weight losses in different temperature ranges are reported in Table 1. By considering the pure components, it is evident that $\mathrm{PHB}$ (curve I in Figure 3) completely degrades in the range 200$300{ }^{\circ} \mathrm{C}$, PA6,6 (curve II in Figure 3b,e) almost completely degrades at temperatures higher than $300{ }^{\circ} \mathrm{C}$, with a residual mass of 6 wt \%, whereas PVA (curve II in Figure 3c,f) degrades in a multistep process from 200 to $550{ }^{\circ} \mathrm{C}$ and has a residual mass of $14 \mathrm{wt} \%$. For both PVA and PA6,6, a small weight loss is recorded at low temperature ascribable to the evaporation of absorbed water because of the high hygroscopic nature of these 


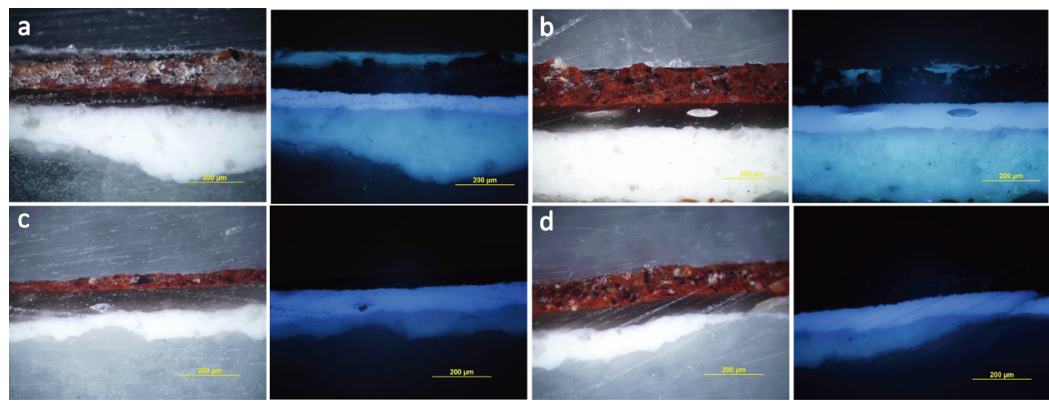

Figure 4. Cross-section microphotographs of mock-ups varnished with dammar, image under visible light (left) and image under UV illumination (right), (a) varnished area before cleaning, (b) after cleaning by PHB-GVL gel and cotton swab, (c) after cleaning by PVA/PHB-GVL gel and cotton swab, (d) after cleaning by PA6,6/PHB-GVL gel and cotton swab.

polymers. The GVL solvent completely evaporated at temperature below $200{ }^{\circ} \mathrm{C}$, as demonstrated by the comparison of the wet and dry gel. With these premises, it is possible to determine the composition of the different materials, both in terms of solvent content and polymer ratios in the composites. The PHB-GVL wet gel (curve II, Figure 3a,d) contains about 92 wt \% of GVL (weight loss $\mathrm{RT}-200{ }^{\circ} \mathrm{C}$ ), the remaining $\mathrm{PHB}$ weight fraction (8\%) degrades in the range $200-300^{\circ} \mathrm{C}$, as expected. In the PA6,6/PHB-GVL system, the wet gel (curve III, Figure $3 \mathrm{~b}, \mathrm{e}$ ) loses $88 \%$ of GVL weight before 200 ${ }^{\circ} \mathrm{C}$ and the remaining weight fraction is composed by $\mathrm{PHB}$ (9\% weight loss $200-300{ }^{\circ} \mathrm{C}$ ) and PA6,6 (3\% weight loss $\left.300-550{ }^{\circ} \mathrm{C}\right)$. Therefore, the polymer content in the PA6,6/ PHB-GVL system is 12 wt \%, which in turns contains 75 wt \% of $\mathrm{PHB}$ and 25 wt $\%$ of PA6,6. The relative content of polymers is in line with the TGA analysis of the dried composite (curve IV, Figure 3b,e) that, albeit still displays a 3\% of residual solvent, contains 80 wt $\%$ of $\mathrm{PHB}$ and 17 wt \% of PA6,6. In the case of the PVA/PHB-GVL system, the wet composite (curve III, Figure $3 \mathrm{c}, \mathrm{f}$ ) is constituted by $89 \%$ of GVL and the remaining weight fraction is the polymer content (PHB + PVA). Here, the discrimination between the two types of polymers is difficult because of the PVA thermal degradation partially overlaps with that of PHB. However, in the dried composite (curve IV, Figure $3 c, f$ ) the weight loss in the range $200-300{ }^{\circ} \mathrm{C}$ is due to the concomitant degradation of $\mathrm{PHB}$ and of PVA, while the weight loss at $300-550{ }^{\circ} \mathrm{C}$ can be ascribable only to the degradation of PVA. By considering that pure PVA loses in this temperature range $71 \mathrm{wt} \%$ of its weight, it can be calculated that in the dried composite the content of PVA is about 27 wt \%. Overall, TGA analysis suggests that both the gel and the composites contain about $90 \mathrm{wt} \%$ of solvent and that in the composites $\mathrm{PHB}$ content is in the range 73-80 wt \% whereas the electrospun polymer amount is in the range 20-27 wt \%, with the PVA/PHB-GVL composite being richer of fibers than the PA6,6/PHB-GVL one. This finding can be explained by considering that the PVA mats used for composite preparation were thicker than PA6,6 mats, as reported in Table $S 1$.

Evaluation of the Cleaning Efficacy and Residuals. In order to investigate the cleaning performance of the different materials, mock-ups varnished with a $40 \mu \mathrm{m}$ thick layer of dammar were used. Cross-sections of paint samples collected from the mock-ups before and after the cleaning treatment were observed with optical microscopy (Figure 4). It can be noted that, after cleaning with either PVA/PHB-GVL or PA6,6/PHB-GVL composites, the dammar varnish completely disappeared, whereas after the application of the $\mathrm{PHB}-$
GVL gel, some fluorescence spots, ascribable to residual dammar, were still visible on the painting surface. A higher cleaning efficacy was thus displayed by the sandwich composites compared to the gel, with no evident differences between the two type of composites.

The high cleaning performance of the composites was confirmed by FTIR microscopy in the ATR mode (Figure 5) performed on the mock-ups surface after $24 \mathrm{~h}$ from a $5 \mathrm{~min}$ treatment. FTIR spectra of dammar before cleaning and of the unvarnished substrate are also displayed for comparison. After cleaning with PHB-GVL gel, the characteristic bands of
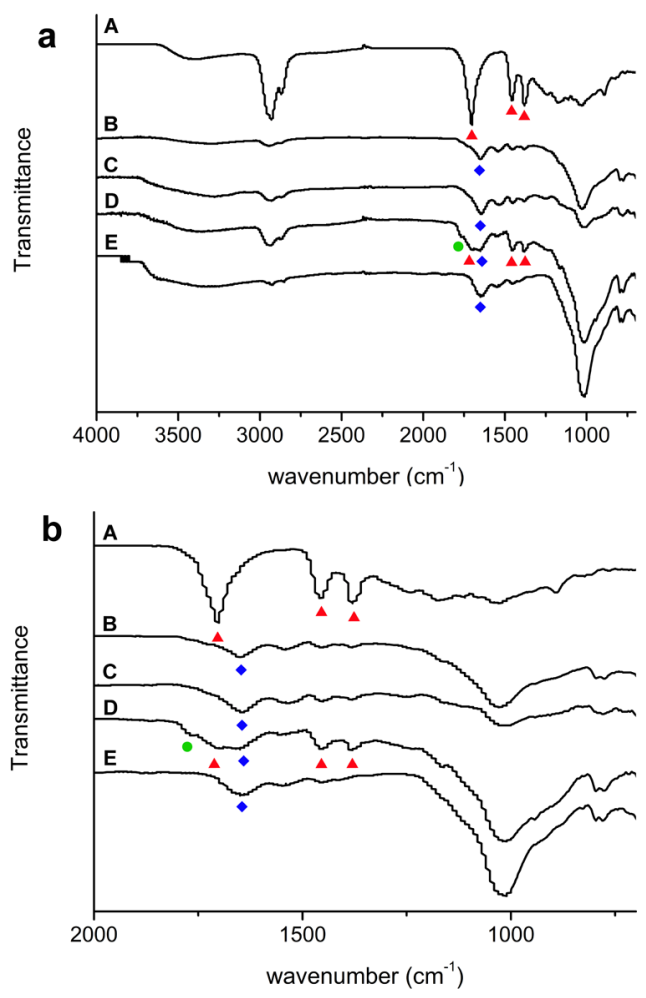

Figure 5. ATR-IR spectra acquired on the surface of the mock-ups: (A) dammar varnish area, (B) after cleaning with PVA/PHB-GVL composite, (C) after cleaning with PA6,6/PHB-GVL composite, (D) after cleaning with PHB-GVL gel, and (E) unvarnished area. The symbol $\boldsymbol{\Delta}$ indicates dammar characteristic bands, the symbol indicates the characteristic bands of glue used as binder in the painting layer above the varnish, and the symbol $\bullet$ indicates the GVL characteristic bands. (a) Spectra in the whole investigated wavelength range and (b) in the range $2000-675 \mathrm{~cm}^{-1}$. 
dammar (red triangles) at $1704 \mathrm{~cm}^{-1}(\mathrm{C}=\mathrm{O}$ stretching) and at 1455 and $1380 \mathrm{~cm}^{-1}\left(\mathrm{C}-\mathrm{H}_{2}\right.$ scissoring) were just reduced. Moreover, residues of GVL were also observed as the band at $1767 \mathrm{~cm}^{-1}$ (green circle, $\mathrm{C}=\mathrm{O}$ stretching) suggests. After the cleaning with the sandwich-like composites, the dammar $\mathrm{C}=$ $\mathrm{O}$ stretching band at $1704 \mathrm{~cm}^{-1}$ completely disappeared and no residue of GVL was observed. In addition, the glue binder characteristic bands (amide I at around $1650 \mathrm{~cm}^{-1}$ and amide II at around $1540 \mathrm{~cm}^{-1}$, blue squares), observed in the unvarnished paint layer, were also detected after cleaning with the composites, thus demonstrating the high efficiency of these new materials in removing the dammar coating, without leaving solvent residues. It is pointed out that no significant differences in the cleaning performance of PVA- and PA6,6based composites were detected.

FTIR analyses in the ATR mode underline also that GVL residues were not detected after the application of the sandwich-like composites. To better quantify the solvent residues left on the painting after cleaning with the different materials HS-SPME was applied. This aspect is of key importance on a practical point of view because residual solvent on the paint surface could lead to a series of adverse effects. The evaluation of the amount of solvent released to the paint layer was aimed at comparing the different cleaning systems, thus acquiring information about their capability to retain the solvent. To make a realistic comparison, because 5 min treatment with $\mathrm{PHB}-\mathrm{GVL}$ gel was not effective in completely removing the varnish, a second application of $5 \mathrm{~min}$ was also carried out for this material, after which the removal of the dammar was complete. In the case of sandwich-like composites, instead, only one 5 min-treatment was enough to achieve the same result in terms of cleaning efficiency. The amount of residual GVL detected after 2 and $24 \mathrm{~h}$ from the treatments are reported in Table 2 . In the case of sandwich-like

Table 2. Amount of GVL Residues (wt \%) after 2 and 24 h from the Cleaning Treatments with Gels and Cotton Swab

$\begin{array}{lccc}\text { sample } & \begin{array}{c}\text { time of } \\ \text { treatment } \\ (\mathrm{min})\end{array} & \begin{array}{c}\text { GVL content at } \\ 2 \mathrm{~h}(\mathrm{wt} \%)\end{array} & \begin{array}{c}\text { GVL content at } \\ 24 \mathrm{~h}(\mathrm{wt} \%)\end{array} \\ \text { PHB-GVL } & 5 & 0.449 \pm 0.120 & 0.273 \pm 0.127 \\ \text { PHB-GVL } & 10 & 0.543 \pm 0.060 & 0.338 \pm 0.001 \\ \text { PA6,6/PHB-GVL } & 5 & 0.271 \pm 0.029 & 0.170 \pm 0.018 \\ \text { PVA/PHB-GVL } & 5 & 0.160 \pm 0.001 & 0.143 \pm 0.021\end{array}$

composites, PA6,6/PHB-GVL cleaned area showed a slightly higher amount of solvent than PVA/PHB-GVL cleaned area after $2 \mathrm{~h}$ from treatment, whereas, after $24 \mathrm{~h}$, both cleaned areas contained a very small amount of residual solvent. Remarkably, in the PHB-GVL gel cleaned area a significantly higher amount of GVL remained when compared to the cleaning with the sandwich composites. The lower amount of solvent found in the case of composites can be the consequence of a slower release of GVL by these types of materials. This finding can be explained considering that, in the case of PHB-GVL gel, the solvent diffuses from the gel to the paint through the entire surface in contact with the paint, whereas, in the case of sandwich composites, a fraction of the surface in contact with the paint is constituted by fibers. The latter prevent the diffusion of the solvent toward the paint, albeit being surrounded by a thin layer of gel that, however, quickly solidify, thus interrupting the diffusion of GVL. In this way the action of the composite materials is more superficial and controlled with respect to the normal gel. Thus, by keeping constant the time of application, the amount of solvent transferred to the paint by the sandwich-like composites is less than that released by the gel. This reduced amount of solvent is, however, enough to swell and soften the dammar that can be easily removed from the paint surface leaving behind no residues, contrary to what observed by the PHB-GVL gel (Figure 4). It is worth mentioning that the different solvent content measured after $2 \mathrm{~h}$ in the areas cleaned by the two composites can be ascribable to the different electrospun layer thickness. Indeed, albeit PVA and PA6,6 fibers have similar morphologies in terms of fiber diameter, the PVA layer is slightly thicker than PA6,6 one, thus providing a higher solvent retention ability. ${ }^{44-46}$

To understand why the sandwich-like composites show higher cleaning efficiency, SEM observation of the samples after cleaning was performed (Figures 6 and 7). Figure 6 reports SEM images of the gel and composite surface before $(\mathrm{a}, \mathrm{d})$ and after $(\mathrm{b}, \mathrm{c}, \mathrm{e}, \mathrm{f})$ cleaning. Both in the case of gel and of composite, the side that came in contact with the varnish is covered by a continuous layer of dammar, that appears as agglomerates of small spherical nanoparticles. In the composites, dammar particles appear to be well in contact with the fibres covered by the gel (Figure 6f). Additional representative SEM images can be found in Figure S5.

Figure 7 shows the cross-sections of organogel $(a-c)$ and composite $(\mathrm{d}-\mathrm{f})$ after cleaning. Here, it is possible to observe

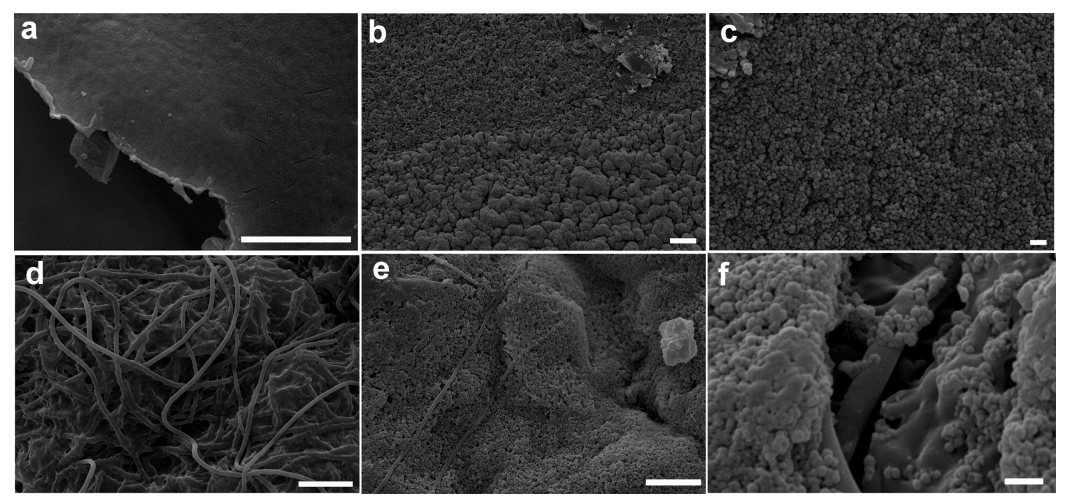

Figure 6. Representative SEM images of: (a) PHB-GVL surface before cleaning; (b,c) PHB-GVL surface after cleaning external; (d) PA6,6/ PHB-GVL composite surface before cleaning; (e,f) PA6,6/PHB-GVL composite surface after cleaning. Scale bar: $10 \mu \mathrm{m}(\mathrm{a}, \mathrm{b}, \mathrm{d}, \mathrm{e}) ; 1 \mu \mathrm{m}(\mathrm{c}, \mathrm{f})$. PVA/PHB-GVL composite surface after cleaning displays the same morphology of PA6,6/PHB-GVL. 


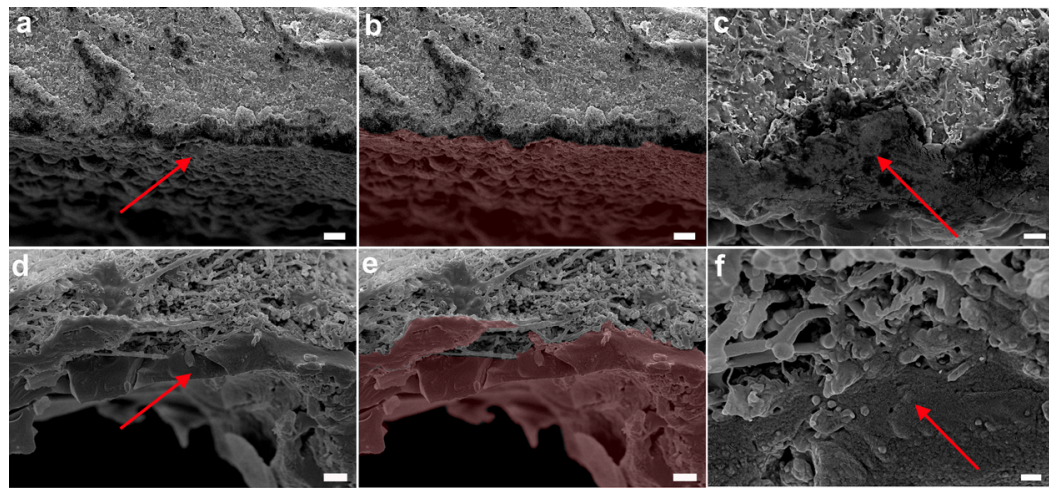

Figure 7. SEM images of material cross-sections after cleaning: $(a-c)$ PHB-GVL gel and (d-f) PA6,6/PHB-GVL composite. Red arrows indicate the side of the section covered by the dammar. In $(\mathrm{b}, \mathrm{e})$ the dammar layer attached to the composite has been colored in red. Scale bar: 10 $\mu \mathrm{m}(\mathrm{a}, \mathrm{b}, \mathrm{d}, \mathrm{e}) ; 2 \mu \mathrm{m}(\mathrm{c}, \mathrm{f})$. PVA/PHB-GVL composite cross-section after cleaning displays the same morphology of PA6,6/PHB-GVL.

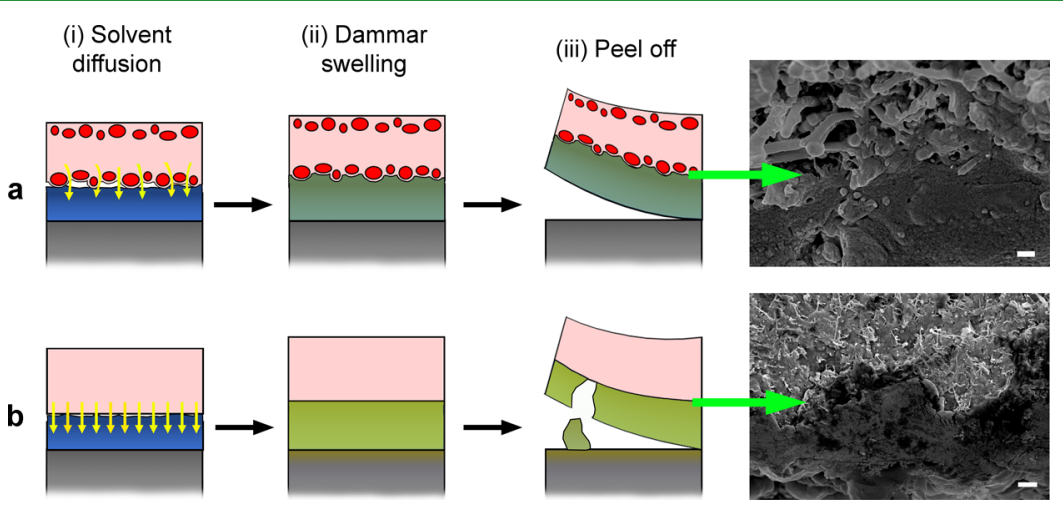

Figure 8. Schematic representation of the mode of action of (a) sandwich-like composites and (b) PHB-GVL organogel for the cleaning of dammar varnish. (i) Solvent diffusion from the gel phase to the varnish (solvent is depicted by yellow arrows): in the sandwich-like composites GVL diffusion is limited by the presence of the fibrous layer (fibre sections are depicted as red circles). (ii) dammar swelling: dammar swells after GVL absorption from the gel phase by following either the rough surface morphology of the composites (a) or the smooth surface of the organogel (b). Higher swelling is expected in the case of organogel compared to the composites, given the higher GVL diffusion from the former. (iii) Removal of the cleaning material by peeling off: dammar layer is effectively peeled off by using composites thanks to its good mechanical adhesion with the rough surface (see SEM image), whereas residual solvent and fragments of dammar can remain on the paint when organogel is used, due to its worse adhesion with the gel (see SEM image).

that the dammar layer is well anchored to the fibrous structure, having partially penetrated the pores of the non-woven (see Figure $7 \mathrm{~d}-\mathrm{f}$ ). Additional representative SEM images can be found in Figure S5. Differently, the dammar layer collected by the PHB-GVL gel appears not well attached to the material (Figure $7 \mathrm{a}-\mathrm{c}$ ).

Figure 8 shows a schematic representation of the possible mode of action of sandwich-like composites compared to pure organogel. The cleaning procedure can be considered as a three-step process: (i) solvent diffusion from the gel phase to the varnish; (ii) dammar swelling and (iii) removal of the cleaning material. In the first step the GVL quickly diffuses from the pure organogel into the dammar layer whereas in the composites the solvent release is slowed down by the presence of the fibers, as previously speculated to explain HS-SPME results. GVL is thus absorbed by the dammar that, as a consequence, swells. The soft dammar can penetrate the pore of the electrospun layer to a certain extent and can thus be easily removed from the paint when the composites are peeled off. Therefore, the micro-structured rough superficial morphology and the interconnected porosity in the sandwich composites provide a higher surface which enables the entrapment of dammar within the porosity and the establishment of a high mechanical adhesion between the varnish layer and the surface composite. This permits to achieve a higher cleaning performance when compared to the single layer gel. The latter, instead, possessing a smoother surface, displays a lower attitude to completely remove the dammar varnish from the substrate and, at the same time, is more susceptible to cohesive failure, with the risk that gel residues may remain on the object after cleaning. This mechanism is supported by the results obtained also with other techniques which, as previously discussed, suggest that the chemical nature of the fibrous component has no evident effect on the cleaning performances. Since the surface of the fibers is completely covered by the PHB component (Figure S4), it turns out that the dammar and the fibers do not directly come in contact during cleaning and the same chemical interactions are established between dammar and composites and dammar and pure gel. Therefore, the role of the fibers is only to provide structural support for the gel and to increase the surface roughness, with the consequent increase of mechanical adhesion between PHB and dammar.

\section{CONCLUSIONS}

This study reports the first attempt to combine electrospun nonwoven fabrics with organogels for cleaning purposes. New materials with a sandwich-like structure, consisting of two 
external layers of electrospun fibers and a core of organogel, have been developed and tested for painting cleaning. The presence of the external electrospun layers confers to the composite new properties and advanced functionalities. First, the electrospun nonwoven exerts the function of mechanically supporting component, thus massively improving the mechanical resistance of the system, as demonstrated by mechanical tests. This aspect is of key importance because facilitates the use and the handling of the cleaning material, especially in the laying and peeling-off procedures, reducing the presence of residual debris on the paints. Cleaning tests and SEM observations highlighted that the presence of a microstructured surface with an interconnected porosity provided by the electrospun layer ensures, on one side, the possibility for the active solvent to diffuse from the inner gel toward the paint surface with a more superficial action than the normal gel and, on the other side, act as anchoring sites for the swollen dammar. Overall, the new developed cleaning systems may be better handled, have better cleaning performances, and are safer toward the cultural object than the neat gel, thanks to their controlled and superficial action. Efforts are currently devoted to further investigate the role played by electrospun materials in cleaning procedures. Thus, new tests, based on the application of PVA and PA with the use of different neat green solvents, are being carried out. Given these exceptional results, such a kind of materials may find application for the cleaning and disinfection of other delicate surfaces, in personal care, and hygiene fields.

\section{ASSOCIATED CONTENT}

\section{(3) Supporting Information}

The Supporting Information is available free of charge at https://pubs.acs.org/doi/10.1021/acsami.0c09543.

Composite geometry; differential scanning calorimetry; rheological properties of PHB-GVL solution; and SEM characterization (PDF)

\section{AUTHOR INFORMATION}

\section{Corresponding Authors}

Silvia Prati - Department of Chemistry "G. Ciamician", Microchemistry and Microscopy Art Diagnostic Laboratory (M2ADL), University of Bologna, 48121 Ravenna, Italy; Email: s.prati@unibo.it

Chiara Gualandi - Department of Chemistry "Giacomo Ciamician" and INSTM UdR of Bologna and Interdepartmental Center for Industrial Research on Advanced Applications in Mechanical Engineering and Materials Technology, CIRI-MAM, University of Bologna, 40126 Bologna, Italy; 이이이.org/0000-0002-2020-1892; Email: c.gualandi@unibo.it

\section{Authors}

Yiming Jia - Department of Chemistry "G. Ciamician", Microchemistry and Microscopy Art Diagnostic Laboratory (M2ADL), University of Bologna, 48121 Ravenna, Italy; Chongqing Cultural Heritage Research Institute, 400013 Chongqing, China

Giorgia Sciutto - Department of Chemistry "G. Ciamician", Microchemistry and Microscopy Art Diagnostic Laboratory (M2ADL), University of Bologna, 48121 Ravenna, Italy
Rocco Mazzeo - Department of Chemistry "G. Ciamician", Microchemistry and Microscopy Art Diagnostic Laboratory (M2ADL), University of Bologna, 48121 Ravenna, Italy

Chiara Samorì - Department of Chemistry "G. Ciamician", University of Bologna, 48123 Ravenna, Italy; (o orcid.org/ 0000-0002-5448-2709

Maria Letizia Focarete - Department of Chemistry "Giacomo Ciamician" and INSTM UdR of Bologna and Health Sciences \& Technologies (HST) CIRI, University of Bologna, 40126 Bologna, Italy; 이이이.org/0000-0002-0458-7836

Complete contact information is available at: https://pubs.acs.org/10.1021/acsami.0c09543

\section{Author Contributions}

The manuscript was written through contributions of all authors. All authors have given approval to the final version of the manuscript.

\section{Notes}

The authors declare no competing financial interest.

\section{ACKNOWLEDGMENTS}

All authors wish to acknowledge the Italian Ministry of University and Research (MIUR) and the China Scholarship Council (CSC) for providing financial support to Y.J.'s overseas study. Giorgia Pagnotta is acknowledge for her assistance in rheological characterization.

\section{REFERENCES}

(1) Baglioni, P.; Carretti, E.; Chelazzi, D. Nanomaterials in Art Conservation. Nat. Nanotechnol. 2015, 10, 287-290.

(2) Chelazzi, D.; Giorgi, R.; Baglioni, P. Microemulsions, Micelles, and Functional Gels: How Colloids and Soft Matter Preserve Works of Art. Angew. Chem., Int. Ed. 2018, 57, 7296-7303.

(3) Baglioni, P.; Berti, D.; Bonini, M.; Carretti, E.; Dei, L.; Fratini, E.; Giorgi, R. Micelle, Microemulsions, and Gels for the Conservation of Cultural Heritage. Adv. Colloid Interface Sci. 2014, 205, 361-371.

(4) Carretti, E.; Bonini, M.; Dei, L.; Berrie, B. H.; Angelova, L. V.; Baglioni, P.; Weiss, R. G. New Frontiers in Materials Science for Art Conservation: Responsive Gels and Beyond. Acc. Chem. Res. 2010, 43, 751-760.

(5) Gettens, R. J.; Stout, G. L. Painting Materials: A Short Encyclopaedia; Dover: New York, 1966.

(6) Schaeffer, T. T. Effects of Light on Materials in Collections: Data on Photoflash and Related Sources; Getty Publications: Los Angeles, CA, 2001.

(7) de la Rie, E. R. Photochemical and Thermal Degradation of Films of Dammar Resin. Stud. Conserv. 1988, 33, 53-70.

(8) Burnstock, A.; Learner, T. Changes in the Surface Characteristics of Artificially Aged Mastic Varnishes After Cleaning Using Alkaline Reagents. Stud. Conserv. 1992, 37, 165-184.

(9) Phenix, A. The Swelling of Artists' Paints in Organic Solvents. Part 1, a Simple Method for Measuring the In-Plane Swelling of Unsupported Paint Films. J. Am. Inst. Conserv. 2002, 41, 43-60.

(10) Phenix, A. Effects of Organic Solvents on Artists' Oil Paint Films: Swelling; Smithsonian Contributions to Museum Conservation, 2013; Vol. 3, pp 69-76.

(11) Stulik, D.; Miller, D.; Khanjian, H.; Khandekar, N.; Wolbers, R.; Carlson, J.; Petersen, W. C. Solvent Gels for the Cleaning of Works of Art: The Residue Question; Dorge, V., Ed.; The Getty Conservation Institute-J. Paul Getty Trust: Los Angeles, 2004.

(12) Baglioni, M.; Rengstl, D.; Berti, D.; Bonini, M.; Giorgi, R.; Baglioni, P. Removal of Acrylic Coatings from Works of Art by Means of Nanofluids: Understanding the Mechanism at the Nanoscale. Nanoscale 2010, 2, 1723-1732. 
(13) Mazzuca, C.; Micheli, L.; Cervelli, E.; Basoli, F.; Cencetti, C.; Coviello, T.; Iannuccelli, S.; Sotgiu, S.; Palleschi, A. Cleaning of Paper Artworks: Development of an Efficient Gel-Based Material Able to Remove Starch Paste. ACS Appl. Mater. Interfaces 2014, 6, 1651916528.

(14) Duncan, T. T.; Berrie, B. H.; Weiss, R. G. Soft, Peelable Organogels from Partially Hydrolyzed Poly(vinyl acetate) and Benzene-1,4-diboronic Acid: Applications to Clean Works of Art. ACS Appl. Mater. Interfaces 2017, 9, 28069-28078.

(15) Duncan, T. T.; Chan, E. P.; Beers, K. L. Maximizing Contact of Supersoft Bottlebrush Networks with Rough Surfaces to Promote Particulate Removal. ACS Appl. Mater. Interfaces 2019, 11, 4531045318.

(16) Samorì, C.; Galletti, P.; Giorgini, L.; Mazzeo, R.; Mazzocchetti, L.; Prati, S.; Sciutto, G.; Volpi, F.; Tagliavini, E. The Green Attitude in Art Conservation: Polyhydroxybutyrate-based Gels for the Cleaning of Oil Paintings. ChemistrySelect 2016, 1, 4502-4508.

(17) Prati, S.; Volpi, F.; Fontana, R.; Galletti, P.; Giorgini, L.; Mazzeo, R.; Mazzocchetti, L.; Samorì, C.; Sciutto, G.; Tagliavini, E. Sustainability in Art Conservation: A Novel Bio-based Organogel for the Cleaning of Water Sensitive Works of Art. Pure Appl. Chem. 2018, 90, 239-251.

(18) Yiming, J.; Sciutto, G.; Prati, S.; Catelli, E.; Galeotti, M.; Porcinai, S.; Mazzocchetti, L.; Samorì, C.; Galletti, P.; Giorgini, L.; Tagliavini, E.; Mazzeo, R. A New Bio-based Organogel for the Removal of Wax Coating from Indoor Bronze Surfaces. Heritage Sci. 2019, 7, 34.

(19) Casoli, A.; Berzioli, M.; Cremonesi, P. The Chemistry of Egg Binding Medium and its Interactions with Organic Solvents and Water, New Insights Into the Cleaning of Paintings: Proceedings from the Cleaning 2010 International Conference, Universidad Politécnica de Valencia and Museum Conservation Institute; Smithsonian Contributions to Museum Conservation, 2013; Vol. 3, pp 39-44.

(20) Cremonesi, P. Rigid Gels and Enzyme Cleaning, New Insights Into the Cleaning of Paintings: Proceedings from the Cleaning 2010 International Conference, Universidad Politécnica de Valencia and Museum Conservation Institute; Smithsonian Contributions to Museum Conservation, 2013; Vol. 3, pp 179-183.

(21) Domingues, J. A. L.; Bonelli, N.; Giorgi, R.; Fratini, E.; Gorel, F.; Baglioni, P. Innovative Hydrogels Based on Semi-interpenetrating p(HEMA)/PVP Networks for the Cleaning of Water-Sensitive Cultural Heritage Artifacts. Langmuir 2013, 29, 2746-2755.

(22) Pacheco, M. F.; Pereira, A. I.; Branco, L. C.; Parola, A. J. Varnish Removal from Paintings Using Ionic Liquids. J. Mater. Chem. A 2013, 1, 7016-7018.

(23) Casoli, A.; Cremonesi, P.; Isca, C.; Groppetti, R.; Pini, S.; Senin, N. Evaluation of the Effect of Cleaning on the Morphological Properties of Ancient Paper Surface. Cellulose 2013, 20, 2027-2043.

(24) Barbabietola, N.; Tasso, F.; Alisi, C.; Marconi, P.; Perito, B.; Pasquariello, G.; Sprocati, A. R. A Safe Microbe-based Procedure for a Gentle Removal of Aged Animal Glues from Ancient Paper. Int. Biodeterior. Biodegrad. 2016, 109, 53-60.

(25) Macchia, A.; Rivaroli, L.; Gianfreda, B. The Green Rescue: A "Green" Experimentation to Clean Old Varnishes on Oil Paintings. Nat. Prod. Res. 2019, 1-11.

(26) Greiner, A.; Wendorff, J. H. Electrospinning: A Fascinating Method for the Preparation of Ultrathin Fibers. Angew. Chem., Int. Ed. 2007, 46, 5670-5703.

(27) Barhoum, A.; Pal, K.; Rahier, H.; Uludag, H.; Kim, I. S.; Bechelany, M. Nanofibers as New-generation Materials: From Spinning and Nano-spinning Fabrication Techniques to Emerging Applications. Appl. Mater. Today 2019, 17, 1-35.

(28) Xue, J.; Wu, T.; Dai, Y.; Xia, Y. Electrospinning and Electrospun Nanofibers: Methods, Materials, and Applications. Chem. Rev. 2019, 119, 5298-5415.

(29) Gualandi, C.; Celli, A.; Zucchelli, A.; Focarete, M. L. Nanohybrid Materials by Electrospinning. Adv. Polym. Sci. 2014, 267, 87-142.
(30) Kenry; Lim, C. T. Nanofiber Technology: Current Status and Emerging Developments. Prog. Polym. Sci. 2017, 70, 1-17.

(31) Agarwal, S.; Wendorff, J. H.; Greiner, A. Use of Electrospinning Technique for Biomedical Applications. Polymer 2008, 49, 56035621.

(32) Persano, L.; Camposeo, A.; Tekmen, C.; Pisignano, D. Industrial Upscaling of Electrospinning and Applications of Polymer Nanofibers: A Review. Macromol. Mater. Eng. 2013, 298, 504-520.

(33) Xu, S.; Deng, L.; Zhang, J.; Yin, L.; Dong, A. Composites of Electrospun-fibers and Hydrogels: A Potential Solution to Current Challenges in Biological and Biomedical Field. J. Biomed. Mater. Res., Part A 2016, 104, 640-656.

(34) Butcher, A. L.; Offeddu, G. S.; Oyen, M. L. Nanofibrous Hydrogel Composites as Mechanically Robust Tissue Engineering Scaffolds. Trends Biotechnol. 2014, 32, 564-570.

(35) Shapiro, J. M.; Oyen, M. L. Hydrogel Composite Materials for Tissue Engineering Scaffolds. Jom 2013, 65, 505-516.

(36) Gualandi, C.; Bloise, N.; Mauro, N.; Ferruti, P.; Manfredi, A.; Sampaolesi, M.; Liguori, A.; Laurita, R.; Colombo, V.; Visai, L.; Focarete, M. L.; Ranucci, E. Poly-l-Lactic Acid Nanofiber-Polyamidoamine Hydrogel Composites: Preparation, Properties, and Preliminary Evaluation as Scaffolds for Human Pluripotent Stem Cell Culturing. Macromol. Biosci. 2016, 16, 1533-1544.

(37) Tonsomboon, K.; Oyen, M. L. Composite Electrospun Gelatin Fiber-alginate Gel Scaffolds for Mechanically Robust Tissue Engineered Cornea. J. Mech. Behav. Biomed. Mater. 2013, 21, 185194.

(38) Cui, Z.; Wright, L. D.; Guzzo, R.; Freeman, J. W.; Drissi, H.; Nair, L. S. Poly(d-lactide)/poly(caprolactone) nanofiber-thermogelling chitosan gel composite scaffolds for osteochondral tissue regeneration in a rat model. J. Bioact. Compat. Polym. 2013, 28, $115-125$.

(39) McMahon, R. E.; Qu, X.; Jimenez-Vergara, A. C.; Bashur, C. A.; Guelcher, S. A.; Goldstein, A. S.; Hahn, M. S. Hydrogel-electrospun Mesh Composites for Coronary Artery Bypass Grafts. Tissue Eng., Part C 2011, 17, 451-461.

(40) Ekaputra, A. K.; Prestwich, G. D.; Cool, S. M.; Hutmacher, D. W. Combining Electrospun Scaffolds with Electrosprayed Hydrogels Leads to Three-dimensional Cellularization of Hybrid Constructs. Biomacromolecules 2008, 9, 2097-2103.

(41) Gensheimer, M.; Brandis-Heep, A.; Agarwal, S.; Thauer, R. K.; Greiner, A. Polymer/bacteria Composite Nanofiber Nonwovens by Electrospinning of Living Bacteria Protected by Hydrogel Microparticles. Macromol. Biosci. 2011, 11, 333-337.

(42) Stevens, M. M.; George, J. H. Exploring and Engineering the Cell Surface Interface. Science 2005, 310, 1135-1138.

(43) Cennini, C. Il Libro Dell'arte, (A Cura di F. Brunello); Vicenza; Pozza, N., Ed.; Routledge, 1982.

(44) Wang, N.; Burugapalli, K.; Song, W.; Halls, J.; Moussy, F.; Zheng, Y.; Ma, Y.; Wu, Z.; Li, K. Tailored fibro-porous structure of electrospun polyurethane membranes, their size-dependent properties and trans-membrane glucose diffusion. J. Membr. Sci. 2013, 427, 207217.

(45) Kim, G.; Yoon, H.; Park, Y. Drug Release from Various Thicknesses of Layered Mats Consisting of Electrospun Polycaprolactone and Polyethylene Oxide Micro/nanofibers. Appl. Phys. A 2010, 100, 1197-1204.

(46) Essalhi, M.; Khayet, M. Self-sustained Webs of Polyvinylidene Fluoride Electrospun Nanofibers at Different Electrospinning Times: 1. Desalination by Direct Contact Membrane Distillation. J. Membr. Sci. 2013, 433, 167-179. 